\title{
Syntactic Maxi-Accidents in Spontaneous \\ Speech of Middle-Class Speakers of English
}

\author{
Karen Velyan \\ Yerevan Brusov State University of \\ Languages and Social Sciences
}

\begin{abstract}
Spontaneous spoken language is known to be rich in fragmented and nonintegrated chunks of speech. The latter are the result of syntactic "accidents", which are indispensible elements of spontaneous talk. Caused by a variety of pragmatic factors, syntactic accidents differ in their formal, lexical, and distributional features. With these features in view, we single out three main varieties of syntactic accidents: 1. maxi-accidents, 2. mini-accidents and 3. micro-accidents, which collectively constitute one whole paradigm.

Within the framework of the present article, the main focus of the analysis is on maxi-accidents in spontaneous talk of middle-class native speakers of English. Based on the empirical data, the analysis outlines the key functional properties of maxi-accidents, such as their frequency of occurrence, positional characteristics and pragmatic reasons that lie behind maxi-accidents.
\end{abstract}

Key words: maxi-accidents, spontaneous talk, distributional properties, planning of ideas, lexical change, interrupted fragment.

\section{Introduction}

Spontaneous and non-spontaneous talks are known to vary in a number of linguistically important respects, including - but not limited to - vocabulary choice, syntactic structures, and intonation contours. Extra-linguistic factors such as time constraints, face-to-face communication, background knowledge have direct correlation with speech production in spontaneous communication. In this regard, one of the key distinctions between planned and non-planned 
speech lies in the fact that the latter is mainly organized round unintegrated, that is, disconnected syntactic structures. The latter, otherwise called fragmented syntax (see, for example, Miller and Weinert 2009) appear when there is a break of the flow of surface syntax at the moment of speech. W. Chafe addresses the phenomenon of fragmented syntax in his article «Integration and involvement in speaking, writing and oral literature», emphasizing fragmented syntax arising from breaks as a property of spoken language (Chafe 1982). In our research, we call this kind of breaks «syntactic accidents», which we define as follows: interruptions of the surface syntax in the flow of speech production, generated by pragmatic reasons and performance errors and resulting in syntactic fragments.

Syntactic accidents, however, are far from being homogenous as regards their formal properties, there being different reasons to generate them. Based on lexico-syntactic features, we single out three main varieties of syntactic accidents in our research: maxi-accidents, mini-accidents, and micro-accidents, which collectively make up one whole paradigm. Respectively, all three varieties possess their distinctive lexico-syntactic features. Specifically, maxiaccidents arise when there is a break in the middle or at the beginning of the sentence, with a new sentence following, like in the following illustrations:

1. My perspective on this. You see .. I went .. to a couple of years of undergraduate at UT,...

(interview with J. Duke)

2. I haven't found it.. In different parts, for example, in.. in different um. Employment situations it.. it may be very different. (interview with C. Preston)

Mini-accidents arise when there is a break of the sentence, with the interrupted word or phrase (but not the sentence) repeated in the sequential segment of the sentence: 
1. Of course, since American literature is my field, I think I.. I have a lot of a deep sense of the things that shape our culture and...

(interview with S. Kerr)

2. If I had a chance to live anywhere, I think I would probably.., other than Austin, I would move to New York, probably for all the work opportunities. (interview with J. Duke)

And finally, micro-accidents arise when there is a break in the boundaries of a word in the sentence:

1. ... then it would be a very differ.. difference, then I would say that's been a complete transformation.

(interview with Ch. Tiplady)

2. Yeah, a lot more, so.. social expectations, more conservative views around race and migration and foreigners and all that sort of things.

(interview with E. Russell)

However, these three basic types are not homogenous either and are further subdivided into divergent subtypes. In this article, we will be looking at the formal characteristics of maxi-accidents and the pragmatic reasons that lie behind them.

\section{Objectives of the Analysis}

It is assumed that syntactic accidents may display different formal features in spontaneous talk of representatives of different social classes: upper, middle, and low. From the wider scope of our research perspectives, it was our interest 
to see what kind of syntactic accidents come up to the surface in the talk of middle-class speakers - both males and females. From the narrower scope of the research, we were aimed at carrying out a mixed quantitative-qualitative analysis of syntactic maxi-accidents that arise in spontaneous talk of our target social group - middle-class native speakers of English. In terms of the quantitative analysis, it was our interest to see the frequency of occurrence of different formal types of syntactic accidents. We were also curious to take a closer look at what may trigger interruptions in the talk of middle-class speakers, that is, what factors have immediate correlation with syntactic maxiaccidents.

\section{Data and Methods of the Analysis}

To obtain empirical data for the analysis, a substantial number of informal audio-interviews were conducted with middle-aged (35-60) representatives of middle class in different areas of England (Newcastle / Northumbria), Brighton / Sussex), York City / Yorkshire) and the USA (Austin / Texas), Los Angeles / California), Columbia / South Carolina). Coming from our current objectives, we analyzed 16 interviews (8 interviewees per gender), with the average duration of 6.5 minutes. The interviews were then transcribed into written texts, which became the source for the analysis. To ensure communicative equality, all interviewees were asked the same questions, which have no linguistic relevance, namely: 1 . "Do you think that in the last 15 to 20 years there has been a transformation or at least a change of gender roles in your home city?"; 2. "How do you find social life in your home city?". These two questions are contextually different and assume different content, which would provide different kinds of narrative and, respectively, a wider scope of syntactic structures in responses. In order to find out the varying frequency of maxiaccidents in spontaneous talk of our target social group, we implemented statistic analysis. Dealing with the phenomenon of syntactic accidents, we could not but implement structural analysis. 


\section{Outcomes of the Analysis}

As indicated in the introductory part of the article, each type of syntactic accidents is not homogenous and may display different formal, lexical, and distributional properties. In this part of the article, we will lay out the main findings that came up as a result of our analysis. The overall number of the maxi-accidents turned out to be 88. But this number will get broken down into smaller numbers as we look more closely at the different subtypes of maxiaccidents, which will be presented below.

In terms of frequency of occurrence, it is maxi-accidents with a complete lexical change after the interruption that stand out in spontaneous talk. The overall number of maxi-accidents with a complete lexical change is 39 , which makes up almost half the overall number of maxi-accidents. Let us take a look at the illustrations extracted from different interviews with native speakers (the interrupted fragments are indicated as italic and bold, followed by double dots):

1. I mean.. 'Cause remember the.. the prosecutors, they.. they worked together with the police, you know.

(interview with P. Boham)

2. I haven't found it.. In different parts, for example, in.. in different um. employment situations it. it may be very different.

(interview with C. Preston)

3. It was a good.. Well, it's an interesting organization called "Meet up", and you might want to research this, "Meet up Brighton", "Meet up Newcastle”, "Meet up London".

(interview with Ch. Tiplady) 
It seems obvious from the examples that the interruptions of the initial sentences (I mean.., I haven't found it.., It was a good..) are triggered by the new ideas that "pop up" in the minds of the speakers, which entails the interruption of the preceding sentence, with the latter being left "hanging". The factor of new ideas is also justified by totally different lexical set in the sentences that follow the interrupted segments.

Maxi-accidents with a complete lexical change may also arise because of experiencing difficulty in phrasing and changing the planning of ideas. Otherwise stated, when a speaker finds it difficult to carry on the wording of his discourse down the syntactic "path" that he originally chose, he has to shift to a phrasing which is more likely to better express the idea meant to be conveyed. The following segment of the interview with a speaker from Newcastle would be a good illustration:

L.H. In that, when I was a child, most of the men would be engaged in the coal mining or ship building activities which this region is still ...

K.V. Right.

L.H. ... indeed, where many men were employed, and I am talking about not too long after the Second World War, when, obviously, we could have needed. rebuilding and um. there was.. um. when the employment was not a problem.

(interview with L. Heslop)

As can be seen from the passage, the interruption arises after the predicate there was. Most likely, the speaker found the syntactic structure that he had in his mind inappropriate, so after some hesitation he switched to another syntactic structure and phrased his idea differently, leaving the fragment there was "hanging". The valid indicator of the difficulty the speaker experiences in phrasing is the hesitation mark um, which appears twice in the same passage of the discourse. 
Difficulty in phrasing and, as a consequence, change in planning of ideas may arise at the very beginning of the sentence, which serves as another case of maxi-accidents with a complete lexical change. The overall number of this kind of maxi-accidents turned out to be 26 , which is much smaller than that of the previous maxi-accidents we discussed above (39). As our data indicate, in the vast majority of cases the interrupted element is a conjunction, as exemplified in the following passages from the interviews:

1. And..So I changed my academic focus in Ph. D working in ESL, with that in mind.

(interview with J. Duke)

2. And.. So I think my creative writing is a part of what helps me, helps my students write.

(interview with S. Kerr)

3. But.. I think it depends on the context and the field of.. of the potential.

(interview with P. Boham)

Maxi-accidents may arise with a partial lexical change in the subsequent part. This normally happens when the speaker at some point realizes that he needs to insert contextually important information, so he abandons his original message and fills in the missing information, which, from the speaker's perspective, is needful in making a particular point. The overall number of this subtype of maxi-accidents in our data is 13 , which is twice as little as the previous case (26). The following examples will illustrate the point.

1. In the past, men. . [if the wife had a baby, she got a maternity leave], the man had to come straight to work.

(interview with C. Preston) 
2. People pawn cars longer, people.. [The real estate market has changed], people were moving more, and now they are not.

(interview with T. England)

3. And if one is an older single person, it's probably harder to have an active social life as.. [than it is

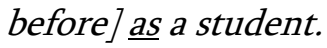

(interview with T. England)

In the first example, the speaker abandons the sentence at the word men, since she feels that contextually relevant information should be provided (if the wife had a baby, she got a maternity leave), and she then makes a transition back to her original statement, continuing with the abandoned word (men). Similar pragmatic interpretations can be offered with respect to examples 2 and 3 , in which the inserted pieces of information - the real estate market has changed, than it is before-interrupt the speaker's narrative discourse. In all the examples, the insertions are followed by the same interrupted word (men... the man, people... people, as... as). This kind of syntactic performance can be explained by the fact that, though left abandoned, the aimed syntactic structure was still in the speaker's mind.

Maxi-accidents with a partial lexical change also arise when the speaker inserts explanatory background information in the narrative, as illustrated in the following examples:

\section{For example, there are more women today who} feel it's possible,.. [and we do work within certain industries], for example, you see more women bus drivers, taxi drivers, whereas that was before, for example, in my profession, mechanics, for example, as well, you read or you see female mechanics who are working. 
2. They still have to .. children, they still have to look after the home, because they tend to be the ones who.. [whether through nature or not] they still tend the ones that are capable a lot more or more capable or, perhaps, are more used to it.

(interview with Ch. Tiplady)

3. Many large organizations. [I used to work for the government, I was a civil servant], and they have the provision for what we call "paternity leave".

(interview with L. Heslop)

From the pragmatic perspective, this functional type of interruption seems to be similar to the one discussed above. The only difference being here is that in the previous case the speakers would have started their discourse with the inserted information if they had remembered it at the starting point of speech. Contrastively, in the last case the speakers make an interruption at some point in speech because they want to introduce some clarification in the discourse, making it semantically more transparent - something that has not been planned before.

The last two subtypes of maxi-accidents with partial lexical change also differ in terms of syntactic arrangement. Thus, in the former case it is the last word that is repeated after the insertion, whereas in the latter case the whole interrupted fragment gets repeated after the insertion. Compare:

People pawn cars longer, $[$ people.. $]$ [The real estate market has changed], (people were moving more, and now they are not.

[For example, there are more women today who feel it's possible,..] [and we do $\sqrt{\text { work }}$ within certain industries], (for example, you see more women) bus drivers, taxi drivers, whereas that was before, for example, in my profession, mechanics, for example, as 
well, you read or you see female mechanics who are working.

In either case, however, the speakers stick to the syntactic structure that they had in mind in the beginning. This fact is very relevant to speakers' memory limitations as reflected in their syntactic performance - "limitations on performance imposed by organization of memory and bounds on memory..." (Chomsky 1970:10).

Finally, in our analysis we single out one more subtype of syntactic maxiaccidents - those with no lexical change in the subsequent part of the narrative. Most typically, syntactic accidents of this kind arise when a speaker runs into some difficulty in phrasing, especially at the beginning of the sentence, which eventually results in the repetition of the interrupted chunk. As far as the frequency of occurrence is concerned, this subtype of maxi-accidents is met rather infrequently. As our data indicate, the overall number turned out to be 10. The following examples can serve as illustrations.

\section{And... I went to.. I went to the academic program} in Russian,... ～(interview with J. Duke)

\section{Well, I like to.. I like to write.}

(interview with S. Kerr)

3. But I think.. I think . for most people it's probably the greatest means of socialization, to get together. (interview with J. Greenwood)

As mentioned above, this subtype of maxi-accidents arises when a speaker is experiencing some difficulty in phrasing his ideas. Still, as compared to the above-discussed cases related to experiencing difficulties, in this particular case the difficulty is of a very temporary character, which is signaled by very short pauses between the repeated segments. We assume that the difficulty lies not in the choice of the appropriate syntactic structure, but rather in the choice of the 
relevant vocabulary to carry on within the limits of the same syntactic structure.

\section{Conclusion}

Thus, within the framework of this article we have presented the outcomes of our analysis of maxi-accidents as a kind of syntactic performance in spontaneous talk. As our empirical data indicate, maxi-accidents in the spontaneous talk of middle-class speakers can take a wide range of forms based on their distributional and lexical characteristics. Different subtypes of maxiaccidents may be generated by different pragmatic reasons and syntactic competences of speakers.

In the whole paradigm of maxi-accidents it is those with a complete change of lexical arrangement in the subsequent narrative that stand out in frequency. They also dominate in terms of the distribution, arising both in the mid- and front positions of the sentence. Of course, the quantitative distribution of maxiaccidents across all social classes will demand further similar analyses with respect to the other social classes.

\section{References:}

1. Chafe, W. (1982) Integration and Involvement in Speaking, Writing, and Oral Literature. // Spoken and Written Language: Exploring Orality and Literacy. Norwood, New Jersey.

2. Chomsky, N. (1970) Aspects of the Theory of Syntax. Cambridge, Massachusetts: M.I.T. Press.

3. Miller, J.; Weinert R. (2009) Spontaneous Spoken Language. Syntax and Discourse. Oxford: OUP.

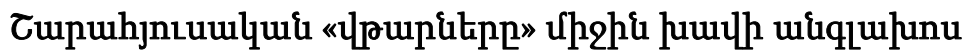 ltiquilhpitiph huiluuwunpuuung hunupnud}

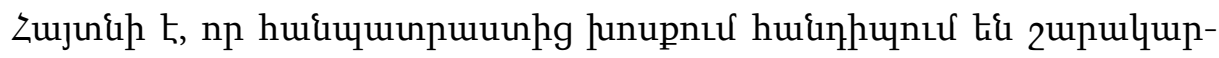

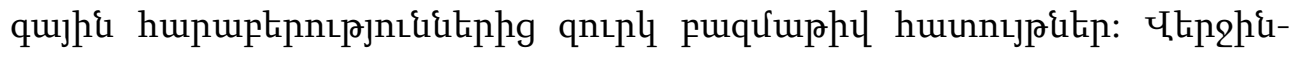




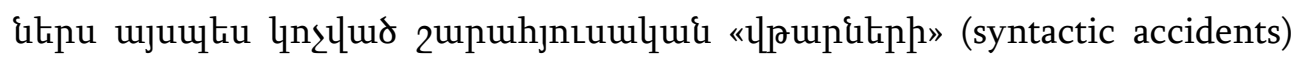

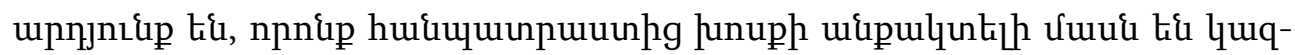

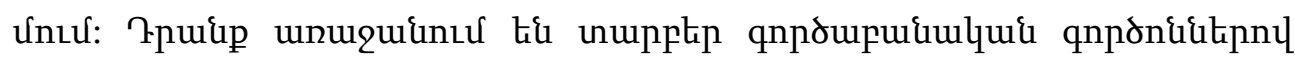

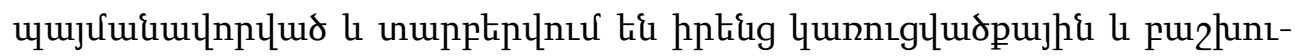

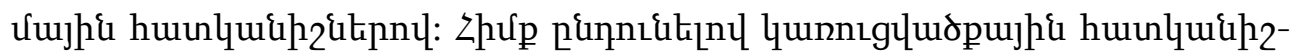

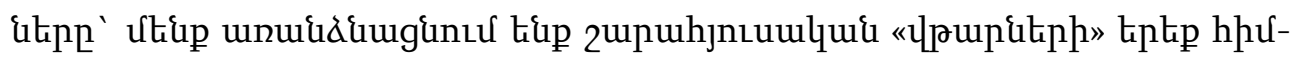

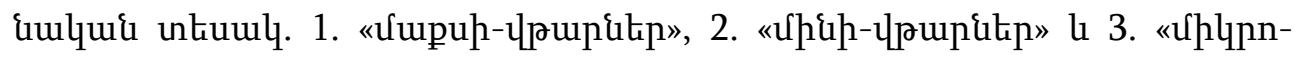

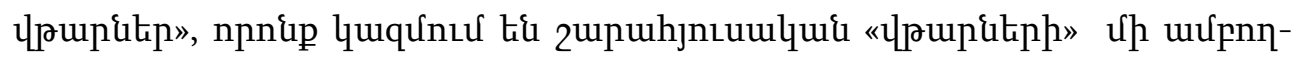
quiluiu hupurgnıg:

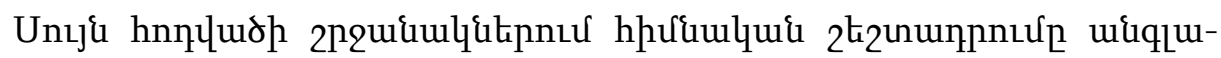

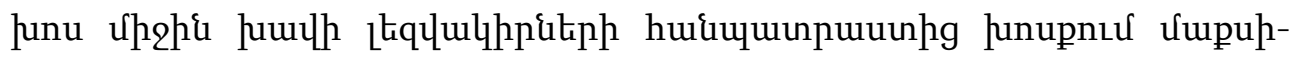

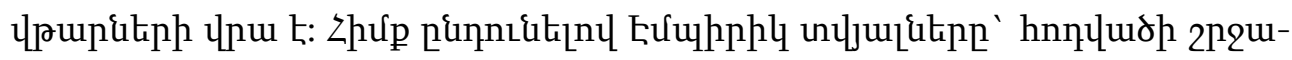

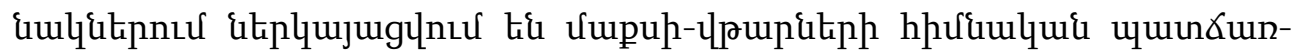

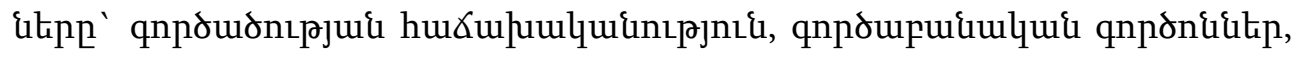

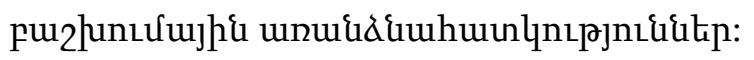

Received by Editorial Board 17.08.2019

Recommended for publication by Reviewers 15.10.2019

Accepted for Print 01.10.2019 